$09 ; 15$

\title{
Исследование скорости релаксации фотовозбужденных молекул индола интерферометрическим методом pump and probe с пикосекундным разрешением
}

\author{
() А.Л. Глазов, А.Д. Ильина, А.А. Сухарев, О.С. Васютинский
}

Физико-технический институт им. А.Ф. Иоффе РАН, Санкт-Петербург

E-mail: glazov.holo@mail.ioffe.ru

Поступило в Редакцию 30 мая 2017 г.

Представлен новый интерферометрический метод исследования динамики фотопроцессов в биологически важных молекулах со сверхвысоким временны́м разрешением. Метод основан на регистрации изменений показателя преломления исследуемого вещества при возбуждении импульсным излучением фемтосекундного лазера с помощью задержанных во времени импульсов излучения того же лазера по методике pump and probe. Высокая чувствительность и стабильность интерферометра позволяют использовать предложенный метод для исследования изменения концентраций короткоживущих возбужденных состояний в растворах биомолекул. Метод применен для раствора индола. Верхняя оценка времени жизни фотовозбужденных состояний молекулы индола составила около $40 \mathrm{ps}$.

DOI: $10.21883 /$ PJTF.2017.18.45034.16891

Фотостабильность биологических объектов разных уровней сложности, начиная с малых биомолекул и заканчивая живыми организмами, является в настоящее время предметом интенсивного изучения [1]. Это в первую очередь касается УФ-области спектра, так как именно это излучение приводит к возникновению мутаций и появлению злокачественных новообразований. С другой стороны, проблема стабильности биообъектов при поглощении световой энергии носит фундаментальный характер [2,3].

Для исследования быстропротекающих процессов релаксации возбужденных состояний широко используются методы, основанные на 
времякорреляционной спектроскопии счета фотонов молекулярной флуоресценции [4-7], а также на технике pump-probe [8]. Особенно высокое временно́е разрешение может быть достигнуто с помощью методов pump-probe, поскольку сегодня доступны лазеры, генерирующие импульсы фемтосекундной длительности, а временну́ю задержку между возбуждающим и зондирующим импульсами можно сделать короче длительности импульса.

Для изучения динамики безызлучательного распада возбужденных состояний биомолекул исследуемое вещество, как правило, растворяется в воде или других растворителях и регистрируется изменение характеристик всего раствора, например его температуры или плотности. Поэтому о динамике переходов в этих случаях можно судить только опосредовано, причем часто характерные времена регистрируемого процесса значительно превосходят время жизни возбужденного состояния. В связи с этим особенно актуальной является разработка методов, способных предоставлять информацию непосредственно о процессах релаксации, в первую очередь безызлучательной, и времени жизни возбужденного состояния.

Поскольку методы pump and probe подразумевают оптическую регистрацию сигнала, основной исследуемой характеристикой объекта является, как правило, показатель преломления. Изменение показателя преломления раствора при поглощении света происходит как непосредственно из-за возбуждения и фотохимических превращений молекул, так и за счет вторичных эффектов, в первую очередь связанных с безызлучательной релаксацией возбужденных состояний, например фототеплового или фотоакустического [9].

В целом изменение показателя преломления при постоянном давлении можно записать как сумму нескольких компонентов

$$
\delta n=\left(\frac{\partial n}{\partial \rho}\right)_{T}\left(\frac{\partial \rho}{\partial T}\right) \delta T+\left(\frac{\partial n}{\partial T}\right)_{\rho} \delta T+\left(\frac{\partial n}{\partial V}\right)_{T} \delta V+\delta n_{P}+\delta n_{K},
$$

где $\rho, T$ и $V$ - плотность, температура и объем объекта соответственно.

Первые два слагаемых связаны с выделением тепла при безызлучательном распаде фотоиндуцированных промежуточных состояний, третье отображает изменение объема вещества при постоянной температуре из-за распределения в веществе акустической волны, $\delta n_{P}$ представляет собой изменение показателя преломления за счет изменения

Письма в ЖТФ, 2017, том 43, вып. 18 
оптической плотности, а $\delta n_{K}$ - изменение показателя преломления за счет оптического эффекта Керра.

Первые три члена выражения (1) связаны с фотоакустическим и фототепловым эффектами в растворе в целом. В настоящей работе регистрируемый сигнал связан с четвертым слагаемым - $\delta n_{P}$, относящимся непосредственно к исследуемому веществу. Неравномерное распределение этой составляющей показателя преломления получило название линзы населенности [10]. Это понятие было введено для описания пространственно неоднородных изменений комплексного показателя преломления при образовании возбужденных состояний молекул после поглощения лазерного излучения. Дисперсия изменения вещественной части показателя преломления раствора за счет возбуждения определенного количества молекул на уровень $\omega_{i}$ может быть записана как [10]

$$
\delta n_{P}=\sum C_{i}\left(\omega_{0}^{2}-\omega_{i}^{2}\right) /\left(\left(\omega_{0}^{2}-\omega_{i}^{2}\right)^{2}+\gamma_{i}^{2} \omega_{i}^{2}\right)
$$

где $C_{i}=\Delta N e^{2} f_{i} / 2 n_{0} m \varepsilon_{0}, \Delta N-$ плотность возбужденных молекул в растворе, $f_{i}, \omega_{i}$ и $\gamma_{i}$ - сила осциллятора, частота максимума и ширина соответствующей линии поглощения, $m$ и $e-$ масса и заряд электрона, $n_{0}$ - невозмущенный показатель преломления раствора. Диапазон дисперсии показателя преломления значительно шире, чем диапазон спектра поглощения, поэтому возможно наблюдение этого вклада на длинах волн зондирующего излучения, лежащих далеко от области поглощения.

Необходимость учета изменения показателя преломления в фотоакустических методах была высказана впервые в работе [11] и затем развита в [10] при исследовании молекул пентацена в молекулярных кристаллах п-терфенила. В этой работе регистрировался фотоакустический сигнал при оптическом возбуждении молекул пентацена пикосекундным лазером с плотностью мощности $500 \mathrm{MW} / \mathrm{cm}^{2}$. Влияние возбужденных состояний проявлялось в виде дополнительного сильного поглощения с возбужденных состояний на той же длине волны $532 \mathrm{~nm}$. Таким образом, влияние было только на мнимую часть показателя преломления. В работах Terazima и др. [12] было продемонстрировано влияние линзы населенности на фотоакустический сигнал в органических растворах. В последнее время этому вопросу уделяется внимание при исследовании лазерных материалов методом тепловой линзы $[13,14]$. 
Следует отметить, что в упомянутых работах учет влияния линзы населенности носил коррекционный характер при интерпретации фотоакустических сигналов. В настоящей работе предложено исследовать возбужденные состояния биологически важных молекул в растворах исключительно на основе эффекта линзы населенности. В качестве объекта исследования использовался раствор индола в пропиленгликоле.

В эксперименте использовался импульсный титан-сапфировый лазер MaiTai (Spectra Physics), излучение которого могло перестраиваться в спектральном диапазоне 690-1040 $\mathrm{mm}$. Лазер генерировал импульсы длительностью $80 \mathrm{fs}$ с частотой повторения $80 \mathrm{MHz}$. Возбуждение молекул индола из основного электронного состояния в состояния ${ }^{1} L_{a}$ и ${ }^{1} L_{b}[15]$ осуществлялось при двухфотонном поглощении излучения второй гармоники лазера с длиной волны $400 \mathrm{~nm}$, а для детектирования сигнала использовалось излучение основной гармоники с длиной волны $800 \mathrm{~nm}$. При этом импульсы зондирующего излучения задерживались во времени с помощью оптической линии задержки с шагом 1 ps. В результате предельное временно́е разрешение установки оказалось меньше характерных времен исследуемых процессов релаксации. Общая схема экспериментальной установки показана на рис. 1.

Регистрация сигналов осуществлялась интерферометрическим методом с использованием дифференциальной схемы. Использованная оптическая схема детектирования фотоакустического сигнала, приведенная на рис. 1, была впервые предложена в работе [16] для исследования твердых тел. Особенностью этой схемы является использование дифракционных решеток для разведения и сведения лучей интерферометра. Возбуждающее излучение было направлено на кювету с образцом сверху (перпендикулярно плоскости распространения дифрагированных зондирующих лучей). При этом ось возбуждающего луча лежала в фокальной плоскости линзы, собирающей зондирующее излучение, и пересекалась только с осью нулевого порядка дифракции зондирующего луча. В реализованной оптической схеме центры дифрагированных зондирующих пучков в фокальной плоскости были разведены на $100 \mu \mathrm{m}$ при радиусе пучков $15 \mu \mathrm{m}$. Радиус возбуждающего луча составлял около $5 \mu \mathrm{m}$. Таким образом, луч в нулевом порядке дифракции является объектным, а лучи в порядках 1 и -1 являются опорными. После сведения лучей второй дифракционной решеткой информация об изменении коэффициента преломления содержится в каждом порядке

Письма в ЖТФ, 2017, том 43, вып. 18 


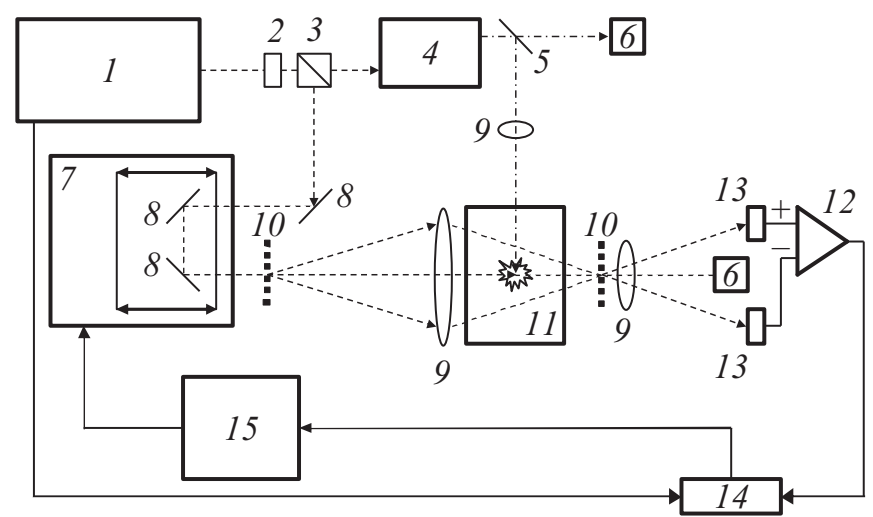

Рис. 1. Схема экспериментальной установки. $1-$ фемтосекундный лазер, $2-$ полуволновая фазовая пластинка, 3 - призма Глана, 4 - удвоитель частоты, 5 - светоделительная пластинка, 6 - измеритель мощности, 7 - линия задержки, 8 - зеркало, 9 - линзы, 10 - дифракционные решетки, $11-$ кварцевая кювета, 12 - фотоэлектронный умножитель со счетчиком фотонов, 13 - фотодиоды, 14 - синхронный детектор, 15 - персональный компьютер.

дифракции, но сигналы в порядках дифракции 1 и -1 на второй решетке находятся в противофазе и позволяют осуществить дифференциальную схему.

Оптическая схема предложенного интерферометра отличается высокой стабильностью по отношению к механическим вибрациям элементов, а близость путей распространения опорных и объектного пучков обеспечивает устойчивость к вариациям параметров исследуемой и окружающей сред. Уровень шумов в сигнале, согласно измерениям, не превышал $0.5 \mathrm{mrad}$ набега фазы в объектном луче.

В качестве образца использовался спиртовой раствор индола концентрации $60 \mathrm{~g} / 1$, разведенный в пропиленгликоле в соотношении $1: 10$ при комнатной температуре. Спиртовой раствор после приготовления отфильтровывался через фильтры $(0.45 \mu \mathrm{m})$. Получающаяся при этом концентрация молекул индола в растворе составляла $3 \cdot 10^{19} \mathrm{~cm}^{-3}$. Для проведения измерений раствор наливался в кварцевую кювету с четырьмя прозрачными стенками шириной $17.7 \mathrm{~mm}$ в направлении распространения лазерного луча зондирования.

Письма в ЖТФ, 2017, том 43, вып. 18 


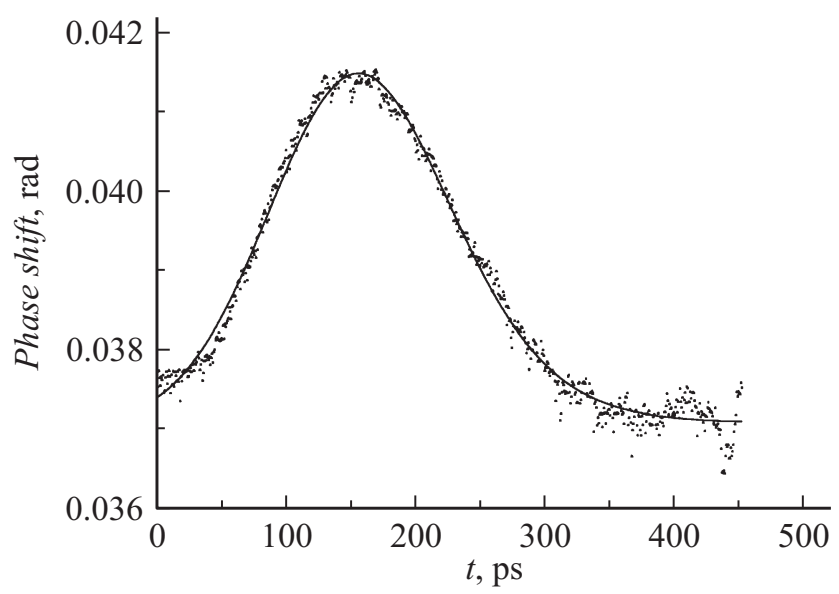

Рис. 2. Зависимость интегрального фазового набега в растворе индола от времени задержки зондирующего лазерного импульса относительно возбуждающего. Экспериментальные данные и результаты подгонки параметров теоретической модели (сплошная линия).

В ходе эксперимента была получена представленная на рис. 2 зависимость интегрального набега фазы в объектном луче от времени задержки зондирующего импульса относительно возбуждающего при мощности последнего $16 \mathrm{~mW}$. Поскольку измерения проводились на пикосекундных масштабах времени, регистрируемые изменения показателя преломления являются следствием исключительно изменения локальной концентрации возбужденных состояний исследуемого вещества, так как все тепловые и акустические процессы, индуцируемые возбуждающим излучением, протекают на существенно бо́льших масштабах времен и вносят фоновый вклад в детектируемый интерференционный сигнал. Таким образом, полученная зависимость позволяет судить о динамике распада фотовозбужденных молекул индола.

Полученная экспериментальная зависимость представляет собой свертку реальной динамики концентрации фотовозбужденных состояний индола и аппаратной функции, которая может быть также обусловлена процессами нелинейного поглощения с участием возбуждающего и зондирующего импульсов. В предположении об одноэкспоненциальном

Письма в ЖТФ, 2017, том 43, вып. 18 
характере распада возбужденных состояний и гауссовой аппаратной функции была выполнена аппроксимация экспериментальных данных, задаваемая выражением

$$
I(t)=I_{0}+I_{1} \int_{-\infty}^{t} \exp \left(-\frac{\left(t-t_{1}-t_{0}\right)^{2}}{T_{1}^{2}}\right) \exp \left(-\frac{t-t_{1}}{T_{2}}\right) d t_{1}
$$

где $I_{0}, I_{1}, t_{0}, T_{1}, T_{2}-$ подгоночные параметры. При этом получены следующие характерные времена исследуемого процесса: $T_{1}=90.1 \pm 0.9 \mathrm{ps}, T_{2}=38.8 \pm 2.1 \mathrm{ps}$. Таким образом, время экспоненциального распада фотовозбужденного состояния индола составляет около $40 \mathrm{ps}$.

Таким образом, в работе продемонстрирована возможность исследования динамики сверхбыстрой безызлучательной релаксации фотовозбужденных состояний биомолекул в растворах. Предложенный интерферометрический метод в отличие от применяемых в настоящее время фотоакустических и фототепловых методов позволяет оценивать непосредственно время жизни этих состояний. Метод опробован на примере молекул индола, являющегося хромофором аминокислоты триптофан, для которого впервые оценено время распада короткоживущего возбужденного состояния.

Работа выполнена при финансовой поддержке Российского научного фонда (грант № 14-13-00266).

\section{Список литературы}

[1] Lin M.-F., Tzeng C.-M., Dyakov Yu.A., et al. // J. Chem. Phys. 2007. V. 126. Iss. 24. P. 241104.

[2] Lan Z.G., Komcke W., Vallet V., et al. // J. Chem. Phys. 2005. V. 122. Iss. 22. P. 224315.

[3] Conti I., Garavelli M., Orlandi G. // AIP Conf. Proc. 2007. V. 963. Iss. 2. P. 655-658.

[4] Denicke S., Gericke K. H., Smolin A.G., et al. // J. Phys. Chem. A. 2010. V. 114. Iss. 36. P. 9681-9692.

[5] Herbrich S., Gericke K.-H., Smolin A.G., et al. // J. Phys. Chem. A. 2014. V. 118. Iss. 28. P. 5248-5255.

[6] Herbrich S., Al-Hadhuri T., Gericke K.-H., et al. // J. Chem. Phys. 2015. V. 142. Iss. 2. P. 024310. 
[7] Васютинский О.С., Смолин А.Г. // Оптика и спектроскопия. 2017. Т. 122. № 4. C. 622-626.

[8] Floyd J.S., Haralampus-Grynaviski N., Ye T., et al. // J. Phys. Chem. B. 2001. V. 105. Iss. 7. P. 1478-1483.

[9] Gensch T., Viappiani C. // Photochem. Photobiol. Sci. 2003. V. 2. Iss. 7. P. 699 721.

[10] Nelson K.A., Casalegno R., Dwayne Miller R.J., et al. // J. Chem. Phys. 1982. V. 77. Iss. 3. P. 1144-1152.

[11] Salcedo J.R., Siegman A.E., Dlott D.D., et al. // Phys. Rev. Lett. 1978. V. 41. Iss. 2. P. 131-134.

[12] Terazima M., Hara T., Hirota N. // J. Phys. Chem. 1993. V. 97. Iss. 41. P. 10554 10560.

[13] Ximendes E.C., Silva W.F., Vermelho M.V.D., et al. // Opt. Express. 2015. V. 23. Iss. 12. P. 15983-15991.

[14] Silva J.R., Malacarne L.C., Baesso M.L., et al. // Opt. Lett. 2013. V. 38. Iss. 4. P. $422-424$.

[15] Chopin C.M., Wharton J.H. // Chem. Phys. Lett. 1969. V. 3. Iss. 4. P. 552-555.

[16] Glazov A.L., Muratikov K.L. // Int. J. Optoelectronics. 1989. V. 4. Iss. 6. P. 589-598. 